Sharma, T. (1999) Cognitive effects of conventional and atypical antipsychotics in schizophrenia. British Journal of Psychiatry, 174 (suppl. 38), 44-5I.

W. Kaiser Krankenhaus Spandau, Department for Psychiatry and Psychotherapy, 13578 Berlin, Germany

Author's reply: I thank Dr Kaiser for drawing attention to the relationship between cognitive function and quality of life in schizophrenia. Dr Kaiser does not find any relationship with a single test that he uses to assess cognitive function (the WCST) and a German short form of the Lancashire Quality of Life Profile and thus goes on to suggest that there is no relationship. However, there is evidence that such a relationship does exist (Addington \& Addington, 1999). Dr Kaiser feels that Heinrichs' Quality of Life Scale (QLS) is an assessment of clinical judgements of negative symptoms but a detailed look at the scale reveals that the four sub-scales of the QLS do indeed measure interpersonal relationships, instrumental role functioning and common objects and activities, among others. It is true that this is an interviewer rating scale and it would be better to have subjective ratings of quality of life. We have indeed carried out such a study and our (as yet unpublished) results show an association between quality of life, as measured by the Lancashire Quality of Life Profile that Dr Kaiser refers to, and measures of cognitive flexibility, verbal ability and verbal memory. Perhaps if Dr Kaiser had used more than one test to assess cognitive functioning in his patients, he may have found an association, as the WCST measures only one aspect of cognitive function. Meanwhile, his point of using subjective measures of quality of life is well taken.

Addington, J. \& Addington, D. (1999) Neurocognitive and social functioning in schizophrenia. Schizophrenia Bulletin, 25, 173-182.

T. Sharma Section of Cognitive Psychopharmacology, Institute of Psychiatry, De Crespigny Park, Denmark Hill, London SE5 8AF

\section{Antidepressant response reversed by interferon}

A 31-year-old woman with depression lost her previously good response to antidepressants (paroxetine plus trazodone) when treated with interferon alpha. We suggest this occurred as a result of the anti-serotonergic actions of interferons.

The single woman was referred by her general practitioner in September 1996 with several years' history of melancholic depression. At presentation she satisfied full clinical criteria for non-psychotic major depressive disorder. Her medical history included ongoing problems with complex partial and generalised epileptic seizures, seronegative arthritis, irritable bowel syndrome and migraine. A paternal uncle suffered from schizophrenia but there was no other family history of psychiatric illness. She had been a university student but discontinued her studies as a result of her depression.

At presentation her daily medication included dothiepin $150 \mathrm{mg}$, carbamazepine $500 \mathrm{mg}$, lamotrigine $50 \mathrm{mg}$, mebeverine $405 \mathrm{mg}$, plus sumatriptan $50 \mathrm{mg}$ and dihydrocodeine-paracetamol as required. Her antidepressant was changed from dothiepin to the selective serotonin reuptake inhibitor (SSRI) paroxetine, increased to $50 \mathrm{mg}$ daily, and trazodone $50 \mathrm{mg}$ at night. There followed a dramatic and sustained improvement in her mood and other depressive symptoms.

In June 1997 she was diagnosed as having essential thrombocythaemia with a platelet count of $1400 \times 10^{9} / 1$. Although distressed by the diagnosis, no return of her depressive symptoms was seen. Following unsuccessful treatment with dipyridamole, interferon alpha was prescribed by her haematologist. She was given 3 million units, stabilised at three times weekly after her platelet count fell to $700-800 \times 10^{9} / \mathrm{l}$. She experienced the usual flu-like symptoms, and after three months noted the recurrence of depression with a similar profile and severity as that seen prior to treatment with paroxetine.

After six months of disabling depression, refractory to paroxetine plus increased doses of trazodone and cognitive therapy, she was admitted to hospital in May 1998. She was reviewed by her haematologist who discontinued interferon as a result of the depression and started hydroxyurea $1000 \mathrm{mg}$ daily. After two weeks this was changed to anagrelide $500 \mu \mathrm{g}$ twice daily (prescribed on a named-patient basis) together with atenolol $50 \mathrm{mg}$ daily to reduce associated migraines. Her platelet count was around $400 \times 10^{9} / 1$. She had 11 bilateral electroconvulsive therapy (ECT) treatments, administered twice weekly, and had a good response. At the end of treatment she described her mood as being $90 \%$ back to normal. She continued on paroxetine $50 \mathrm{mg}$ daily and trazodone $150 \mathrm{mg}$ at night and has remained psychiatrically well to date.
Interferon alpha is associated with a risk of depression, in some cases requiring discontinuation of treatment (McDonald et al, 1987). Treatment of interferon-induced depression has yet to be evaluated by controlled trials, but case reports have shown the benefits of antidepressants (Goldman, 1994).

A notable feature of this case is that interferon alpha appeared to reverse a preexisting antidepressant response to paroxetine. This may be understood in terms of interferon's capacity to impair serotonin synthesis by inducing enzymes that degrade the serotonin precursor tryptophan (Werner-Felmayer et al, 1989). Previous research has demonstrated that dietary tryptophan depletion can strikingly reverse the antidepressant effect of SSRIs (Delgado et al, 1991).

The clinical improvement seen in the present case following hospitalisation may be related to ECT, interferon discontinuation, or both. Although discontinuation often gradually relieves interferon-induced depression, the rapidity and extent of response in the present case suggests at least some effect of the ECT. In contrast to the SSRIs, the antidepressant response to ECT appears resilient to tryptophan depletion (Cassidy et al, 1997). We therefore suggest that ECT is more likely than SSRIs to be effective in interferoninduced major depression.

Cassidy, F., Murry, E., Weiner, R., et al (1997) Lack of relapse with tryptophan depletion following successful treatment with ECT. American Journal of Psychiatry, $\mathbf{1 5 4}$ $1151-1152$

Delgado, P., Price, L., Miller, H., et al (199I) Rapid serotonin depletion as a provocative challenge test for patients with major depression. Psychopharmacology Bulletin, 27, 321-330.

Goldman, L. (1994) Successful treatment of interferonalpha-induced mood disorder with nortriptyline. Psychosomatics, 35, 4I2-413.

McDonald, E., Mann, A. \& Thomas, H. (1987) Interferons as mediators of psychiatric morbidity. Lancet, 2I, II75- II78.

Werner-Felmayer, G., Werner, E. R., Fuchs, D., et a (1989) Characteristics of interferon induced tryptophan metabolism in human cells in vitro. Biochimica et Biophysica Acta, Series on Molecular Cell Research, I0I2, 140-147.

\section{R. H. McAllister-Williams, A. H. Young}

Department of Psychiatry, University of Newcastle uponTyne, Leazes Wing, Royal Victoria Infirmary, Newcastle uponTyne NEI 4LP

D. B. Menkes Department of Psychological Medicine, University of Otago, PO Box 913, Dunedin, New Zealand 